\title{
Sectoral and regional determinants of firm dynamics in developing countries: evidence for low-, medium- and high-tech manufacturing in Argentina
}

\author{
Carla Daniela Calá ${ }^{1}$
}

\begin{abstract}
This study analyses the determinants of firm dynamics in developing countries, using Argentina as an illustrative case. It explains firm entry and exit at the regional level, distinguishing three groups of manufacturing activities: low-, medium- and high-tech. The study finds that both region- and sector- specific determinants explain firm dynamics, but the impact is not homogeneous across sectors. In particular, for low-tech industries, there is a need for explanatory variables as a proxy for the specificities of developing economies (poverty, informal economy and idle capacity). There is also evidence of a core-periphery pattern according to which agglomeration economies and previous entries/exits have different effects in core and peripheral regions. These results are relevant for policymakers in developing countries, who should take into account not only the specificities of such economies, but also the regional heterogeneity both in terms of the level of development and industrial composition within the country.
\end{abstract}

\section{Keywords}

Industrial enterprises, manufacturing enterprises, developing countries, case studies, enterprise development, statistical data, econometric models, Argentina

\section{JEL classification}

R12, R30, C33

\section{Author}

Carla Daniela Calá is a teacher and researcher at the Faculty of Economic and Social Sciences of the National University of Mar del Plata, Argentina. Email: dacala @mdp.edu.ar.

\footnotetext{
The author thanks Miguel Manjón Antolín and Josep-Maria Arauzo-Carod for their support, detailed comments and suggestions, and the anonymous referee for providing useful suggestions and constructive comments. The author also acknowledges the Employment and Business Dynamics Observatory in the Ministry of Labour, Employment and Social Security of Argentina for providing the dataset.
} 


\section{Introduction}

There is extensive literature on the regional determinants of entry and exit of manufacturing firms. This interest is explained not only by the direct impact of new firms on employment and production, but also by their indirect effects on market efficiency, firm productivity, innovation and, ultimately, economic growth (Audretsch and Keilbach, 2005). However, this literature has not been sufficiently complemented by works on sectoral determinants to account for the fact that regional determinants of new firm formation vary among manufacturing industries. Thus, following the seminal work of Audretsch and Fritsch (1999), a number of studies have taken into account both regional and sectoral dimensions to adequately assess the impact of regional characteristics on firm dynamics and to consider heterogeneity at different levels. ${ }^{2}$ Those studies confirm that regional factors determining new firm formation do differ between manufacturing industries (Carree, Santarelli and Verhuel, 2011) and that certain regional conditions may stimulate new firm formation in some industries but deter start-ups in others. As a result, certain policy instruments may encourage start-ups, but not necessarily in the types of industries desired by policymakers (Audretsch and Fritsch, 1999).

Remarkably, studies on the regional and sectoral determinants of firm entry and exit are limited to developed countries, while much less research has focused on developing countries even though these countries are expected to become key players in the world economy, since it is widely assumed that they will noticeably increase their share of output over the next decades (Wilson and Purushothaman, 2006). More precisely, studies on developing countries either focus on industry (Lay, 2003; Wang, 2006; Günalp and Cilasun, 2006; Ozturk and Kilic, 2012) or on regional determinants (Naudé and others, 2008; Santarelli and Tran, 2012; Calá, Arauzo-Carod and Manjón-Antolín, 2015 and 2016). Thus, this would appear to be the first attempt to quantify regional determinants of firm entry and exit in different manufacturing industries of a developing country.

The aim of this study is to provide useful information for policymakers in developing economies, who are interested in designing public policies to promote the emergence (and survival) of new firms countrywide. To that end, Argentina is used as an illustrative case to explain firm entry and exit at the regional level, distinguishing three groups of manufacturing activities: low-, medium- and high-tech. First, the study evaluates whether sectoral and regional determinants of entry and exit differ between sectors. Second, it takes into account the specificities of developing countries by adding indigenous factors, such as poverty levels, the size of the informal sector, idle capacity or regional structural heterogeneity.

The study concludes that both region- and sector-specific determinants explain firm dynamics, but the impact is not homogeneous across different groups of industries. In particular, the variables that are a proxy for the specificities of Argentina as a developing country (poverty level, informal sector size and idle capacity) impact mostly on low-tech entries and exits. There is also evidence of a core-periphery pattern that is relevant for all groups of industries. The results suggest that firm formation policies in developing countries should account not only for the specificities of such economies, but also for regional heterogeneity both in terms of the level of development and the industrial composition within the country.

The paper is divided into five sections. The following section briefly reviews the empirical literature on the regional determinants of firm entry and exit in both developed and developing economies. It also examines why some regional factors may have a different impact in developed and developing countries. Section III describes firm dynamics in Argentina during the period of interest, as well as the dataset, the empirical strategy and the econometric model. Section IV presents the main results and section $\mathrm{V}$, the conclusion.

2 These studies are: Arauzo-Carod and others (2007), focusing on Spain; Carree, Santarelli and Verhuel (2011) on Italy; Fotopoulos and Spence (1998) on Greece; Fritsch and Falck (2007) on Germany; Nurmi (2006) on Finland and Nyström (2007) on Sweden. 


\section{Determinants of firm entry and exit: theory and evidence}

\section{Developed countries}

The significant variations in regional entry and exit patterns have been explained in the literature by differences in some regional characteristics: labour markets; industrial structure; and spatial concentration of economic activities and individuals. ${ }^{3}$

With regard to differences in the labour market, the focus in the literature has been on the effects of unemployment, wages and the educational level of the workforce. The first observation is that there is no consensus on how unemployment affects firm dynamics. According to the "push hypothesis", unemployment has a positive effect on firm entry to the extent that unemployed individuals can create new enterprises. Similarly, when unemployment increases, self-employed individuals have fewer job opportunities and their firms are thus less prone to exit (Carree and Thurik, 1996; Nyström, 2007; Carree, Santarelli and Verhuel, 2008; Santarelli, Carree and Verheul, 2009). By contrast, according to the "pull hypothesis", an increase in unemployment may curtail entry because the unemployed lack entrepreneurial skills and capital. Likewise, since unemployment is a proxy for the level of economic activity, higher unemployment rates may result in an increase in the number of exits (Brixy and Grotz, 2007). Second, with regard to wages, a rise in the cost of labour discourages the entry of new firms and favours exits (Santarelli, Carree and Verheul, 2009). Third, the availability of qualified labour may foster the entry of new firms in industries that require specific skills ${ }^{4}$ (Spilling, 1996).

As regards industrial structure, previous studies have focused on the level of industrial diversification, the industrial tradition, the share of small and medium-size enterprises (SMEs), and the relationship between entries and exits. A more diversified environment promotes both the entry and survival of new firms as it increases the chances of resources being reallocated to new activities when a negative shock occurs (Kosacoff and Ramos, 1999). Furthermore, the industrial tradition may boost current entrepreneurial activities (Rocha and Sternberg, 2005) and deter firm closures, since it is likely that past incumbents developed a favourable business environment and supporting institutions. The share of SMEs is expected to increase regional turbulence, since it fosters both entry and exit. On the one hand, entry costs are lower in areas with a dense network of SMEs, which pay lower wages (thus reducing the opportunity cost of self-employment) and serve as examples for new entrepreneurs (Audretsch, 1995b). On the other hand, as small firms are more likely to exit due to cost disadvantages, exits should be higher in regions with a large proportion of small firms (Fotopoulos and Spence, 1998). This is closely related to the relationship between entries and exits. Entrances may influence exits by increasing the pressure of competition in the market (known as the displacement effect) and, at the same time, firms that abandon the market leave behind niches of unsatisfied consumers, encouraging new companies to enter (the replacement effect). In particular, according to the revolving door phenomenon, many (small) firms exit only a few years after creation (Audretsch, 1995a).

In addition, there tend to be more entries and fewer exits in concentrated areas because firms benefit from local external economies, such as specialized suppliers, thick labour markets and technological spillovers, as well as the physical proximity to consumers (Armington and Acs, 2002; Keeble and Walker, 1994; Littunen, Storhammar and Nenonen, 1998; Reynolds, Storey

\footnotetext{
3 There are also a number of factors which, while important in explaining firm dynamics, cannot easily be included in empirical analyses. This is the case of cultural attitudes towards entrepreneurship (Shapero, 1983) and the role of the government, through public spending on infrastructure or public policies (Reynolds, Storey and Westhead, 1994).

4 It should be borne in mind that people with high human capital are better at discovering and exploiting business opportunities, but at the same time they are more likely to have well-paid jobs and are not necessarily more prone to start new firms (Nyström, 2007).
} 
and Westhead, 1994). However, disagglomeration economies may hamper entry and lead to further exit. This is because a higher density pushes up input prices by increasing competition for scarce resources. ${ }^{5}$

Nevertheless, the impact of these regional characteristics is likely to differ between industries. For example, according to the product life cycle theory (Vernon, 1966), new innovative firms have more to gain from agglomeration economies in the early stages of their existence, since dense urban areas provide better access to capital, skilled labour, infrastructure, information and interaction opportunities with other firms. As their products mature, competition among new firms is based on lower prices, which requires them to lower their input costs. Furthermore, the impact of regional factors such as income levels or unemployment may depend on the elasticity of demand or the level of capital intensity, respectively (Audrestch and Fritsch, 1999). It is perhaps because such differences among industries have been ignored that the relevant literature presents mixed and partly contradictory results (Audrestch and Fritsch, 1999; Fritsch and Falck, 2007).

Only a handful of studies have addressed this limitation (see footnote 2) by considering -in addition to regional variables - some industry-specific factors. In particular, these studies include barriers to entry and exit and have found that the relative importance of location-specific factors is greater in industries with low barriers (Arauzo-Carod and others, 2007; Fotopoulos and Spence, 1998; Fritsch and Falck, 2007; Nurmi, 2006). They also show that while demand for industry-specific products is a key factor in some industries, other activities depend more on the evolution of overall (regional or national) demand. Furthermore, it is unclear how the number of incumbents in the same industry affects firm dynamics. On the one hand, it may attract similar ventures that benefit from positive externalities (known as localization economies); on the other, it may exert a competition effect, preventing entry and increasing exit (Carree, Verheul and Santarelli, 2011).

\section{Developing countries}

Although there is very limited empirical evidence on what determines firm entry and exit in developing countries, it is increasing rapidly. In particular, Lay (2003) and Wang (2006) analyse the entry of new firms using industry level data in Taiwan; the same was done in Turkey (Günalp and Cilasun, 2006; and Ozturk and Kilic, 2012). Calá, Manjón-Antolín and Arauzo-Carod (2016), Naudé and others (2008) and Santarelli and Tran (2012) use regional level data for Argentina, South Africa and Vietnam, respectively. There have also been studies on the determinants of exit in some countries: Lay (2003) and Ozturk and Kilic (2012) use industry level data for Taiwan and Turkey, Calá, Arauzo-Carod and Manjón-Antolín (2015) use regional level data for Argentina; firm level data are used in studies for Ghana (Frazer, 2005), Colombia (Eslava and others, 2006), and Chile (Álvarez and Vergara, 2010 and 2013; and López, 2006).

Interestingly, there are several features of developing economies that may affect firm dynamics and its determinants, which highlights the need for specific empirical research (Bruton Ahlstrom and Obloj, 2008). First, developing countries are generally characterised by macroeconomic instability and intense cyclical variations (Stiglitz, 1998; Ocampo, Rada and Taylor, 2009). Thus, higher vulnerability to macroeconomic shocks is to be expected. This means that after each crisis, a great number of firms enter the growing markets but many of them exit in the following years; consequently, the "revolving

\footnotetext{
5 Exits may also be higher in densely populated areas - see, for example, Buss and Lin (1990), Forsyth (2005) and Huiban (2011) for empirical evidence. There are several reasons for this, including: higher competition in both goods and factors markets (Agarwal and Gort, 1996; Bresnahan and Reiss, 1991); higher chances of finding a job, another entrepreneurial opportunity and/ or selling the firms' assets to another venture (Huiban, 2011); and, as discussed below, more exits in large urban areas which attract more entry and have a large share of young firms.
} 
door" phenomenon may be more intense than is typically observed in developed countries. ${ }^{6}$ In addition, after an economic crisis, existing firms that exploit their idle capacity may have greater aggregate effects on the satisfaction of demand for new goods than new firms (Calá, Manjón-Antolín and Arauzo-Carod, 2016).

Moreover, macroeconomic volatility may mitigate the effect of variables such as the unemployment rate or the industrial tradition. Long-term unemployed individuals may not have the ability, financial resources and/or social capital needed to start a new business (Fritsch and Falck, 2007). However, changes in the conditions that determine profitability (exchange rate, tariffs, credit access or tax policy) and the lack of continuity in industrial policies may reduce the effect of past (dynamic) localization economies on current entry and exit (Calá, Manjón-Antolín and Arauzo-Carod, 2016).

A less developed industrial structure and less saturated markets may affect the relationship between entries and exits. For example, evidence rejecting the replacement effect has been found for Turkey and Taiwan (Günalp and Cilasun, 2006; Lay, 2003). Moreover, exits may actually reflect negative expectations for the evolution of economic activity, deterring entry (Calá, Manjón-Antolín and Arauzo-Carod, 2016). Similarly, agglomeration does not always have a positive association with start-up rates since increased competition and higher barriers to entry may act as disincentives for entrepreneurial activity in core regions (Naudé and others, 2008).

Further, developing countries usually have large informal sectors (Schneider, 2005). At the regional level, the relationship between the size of the shadow economy and the entry rate may be either positive or negative. It will be positive if subcontracting activities create complementarities or if the informal sector encourages entry by acting as a stepping stone (Bennett, 2010) for entrepreneurs to "test the waters" before deciding whether or not to enter the formal sector. In addition, informality may encourage start-ups as the instability and insecurity typical of informal jobs push people towards entrepreneurship. However, a negative association is likely if informal companies compete with formal firms on the basis of lower prices and non-differentiated goods. With regard to exits, a positive relationship may arise if formal firms compete for the same resources as informal firms and/or they become informal when in difficulty. Conversely, a negative association can be expected if formal firms buy inputs from the informal sector, thus lowering costs and/or increasing flexibility.

Another distinctive characteristic of developing economies is the high level of poverty and income disparity, both among individuals and regions. This may hamper the emergence of new (formal) ventures, since the demand for goods and services is smaller, less stable and less diverse. Poverty also affects the supply of entrepreneurs, since the share of people with access to information, business networks and financial resources is limited (Kantis, Angelelli and Moori Koening, 2005).

Lastly, developing countries show marked regional differences in critical economic indicators, with some areas boasting levels of capitalization, technology, productivity and human capital requirements similar to their counterparts in advanced countries (Sunkel, 1978). A direct implication of this "structural heterogeneity" (Cassiolato, Pagola and Lastres, 2009) is that firm entry/exit determinants may differ across the regions of a country. For example, peripheral areas usually lack the critical mass of related firms to create the conditions for external economies in some sectors. As a result, positive agglomeration effects are expected to arise only in central areas. Previous studies on aggregated entry and exit in Argentina have found that the spatial distribution of aggregated entries and exits exhibit a core-periphery pattern (Calá, Arauzo-Carod and Manjón-Antolín, 2015 and 2016).

\footnotetext{
${ }^{6}$ However, this may not occur if less competition and greater monopoly power were to weaken turnover rates and slow down the creative destruction process.
} 


\section{Firm dynamics in Argentina}

\section{Empirical strategy and data}

In order to identify which regional characteristics affect firm entry and exit, the study develops different equations for the number of entries (and exits) in three groups of manufacturing industries: (i) low-tech; (ii) medium-tech; and (iii) high-tech. A general formulation of these equations is:

$$
\begin{gathered}
\text { ENTRY }_{i j t}=f\left(\operatorname{REGION}_{i t} ; \operatorname{INDUSTR} Y_{i j t} ; \text { MACRO }_{t}\right) \\
\text { EXIT }_{i j t}=f\left(\text { REGION }_{i t} ; \operatorname{INDUSTRY} Y_{i j t} ; \text { MACRO }_{t}\right)
\end{gathered}
$$

where $R E G I O N_{i t}$ denotes a group of region-specific factors that vary by year and province; INDUSTRY $i j t$ refers to sector-specific determinants that vary by province, year and group of industries and $M A C R O_{t}$ refers to factors at the national level that vary by year alone.

In order to test if the determinants of firm dynamics in developed countries are of similar importance in Argentina, a set of commonly found determinants are taken as the starting point to explain regional entry and exit in those economies, both at the sectoral and regional level. This provides a first analysis of the differences between developed and developing countries (see Fritsch, Brixy and Falck, 2006 and Ghani, Kerr and O'Connell, 2014 for similar strategies). Based on the information in section II.2, some variables explaining firm entry and exit in developed countries can be expected to have weak statistical significance or to show the opposite sign.

Next, the study examines factors such as the size of the informal economy or the level of poverty, which are potentially important in developing countries but are never considered in studies on developed countries. Finally, the existence of a core-periphery structure is explored by including the products of a dummy identifying the richest provinces with variables that are expected to have different effects in central and non-central regions (agglomeration effects and replacement/displacement effects). This constitutes the second test of the differences between developed and developing countries. One expected outcome is for variables that incorporate some of the specificities of developing countries to have substantial explanatory power. Another is for cross products to have different effects in core and lagged regions.

\section{Entry and exit}

Entry and exit data are taken from the Employment and Business Dynamics Observatory (EBDO) of the Ministry of Labour and Social Security of Argentina. The database contains the number of entries, exits and incumbents based on all manufacturing (formal and private) firms with at least one employee registered with social security. Consequently, the dataset does not contain information on either public or informal employment. Moreover, the Observatory handles changes in firm codes that do not reflect true market entries and exits because a firm is considered closed after 12 consecutive months of not declaring employees. However, spurious exits caused by the displacement of the entire workforce of firms that "exit" to become "new" firms are identified and excluded from the database. Lastly, the analysis is restricted to manufacturing firms declaring that the majority of their workforce is located in the regions under consideration (about $90 \%$ of the total firms in 2008). Branch offices or subsidiaries located in other regions are therefore excluded. On the whole, the Observatory provides the most up-to-date, comprehensive, reasonably long-term and spatially disaggregated data currently available for firm demography studies in Argentina. 
Data are available for the 23 Argentine provinces plus the federal capital, Buenos Aires, with the province of the same name divided into Greater Buenos Aires and the rest of the province. The province of Río Negro was excluded from the study on account of missing data for most of the explanatory variables considered. Consequently, although there are 25 regions in the database, results are ultimately provided for 24 only. Manufacturing is divided into 23 two-digit industries, based on the taxonomy suggested by Katz and Stumpo (2001) and subsequently adapted to a two-digit disaggregation by Katz and Bernat (2011). ${ }^{7}$ These industries are grouped into three categories (high-, medium- and low-tech) according to their level of technological intensity (see annex 1).

The dependent variable is the number of annual entries and exits in each region and group of industries during the period 2003-2008. By using 2003 as the start of the analysis, the study excludes the structural break caused by the economic and political crisis of the end of 2001 that led to the devaluation of the Argentine peso in January 2002 and thus avoids completely distorting the results. The period of analysis ends at 2008, which was the last available year in the EBDO dataset at the time. Table 1 shows the evolution of entries, exits and incumbents over the period of analysis.

Table 1

Argentina: number of entries, exits and incumbents, 2003-2008

\begin{tabular}{|c|c|c|c|c|c|}
\hline Year & Entry & Exit & Incumbents & Entry rate $^{\mathrm{a}}$ & Exit rate $^{b}$ \\
\hline 2003 & 4986 & 2330 & 42754 & $11.7 \%$ & $5.4 \%$ \\
\hline 2004 & 5994 & 2326 & 45234 & $13.3 \%$ & $5.1 \%$ \\
\hline 2005 & 5486 & 2929 & 48317 & $11.4 \%$ & $6.1 \%$ \\
\hline 2006 & 6264 & 3623 & 49987 & $12.5 \%$ & $7.2 \%$ \\
\hline 2007 & 5886 & 4358 & 51796 & $11.4 \%$ & $8.4 \%$ \\
\hline 2008 & 5389 & 5103 & 52417 & $10.3 \%$ & $9.7 \%$ \\
\hline
\end{tabular}

Source: Prepared by the author, on the basis of data from the Employment and Business Dynamics Observatory.

a The entry rate is calculated as the number of entries over the number of incumbents.

b The exit rate is calculated as the number of exits over the number of incumbents.

The high values for entries in 2003-2005 are closely related to the recovery of the Argentine economy after the crisis of 2001-2002. Table 1 shows that the high entry rates from 2003 (around 12\%) declined only at the end of the period, but still remained high (around 10\%). As regards exits, however, after the first two years of stability (2003-2004), the opposite trend was observed, with an average yearly variation rate of $17 \%$. According to the Ministry of Labour, Employment and Social Security (2007), this was largely driven by new ventures in the years immediately following the crisis (both deferred projects and entirely new ventures encouraged by better macroeconomic conditions). Additionally, the slowdown in net entry in 2008 is explained by the international financial crisis, the gradual appreciation of the real exchange rate and domestic tensions (Katz and Bernat, 2011).

Table 2 shows that the spatial distribution of incumbents, entries and exits is not homogeneous, since most are concentrated in the five richest regions (the federal capital city, Gran Buenos Aires, the rest of Buenos Aires province, Santa Fe and Córdoba). Specifically, about $80 \%$ of the workers, incumbents, new ventures and exiting firms are concentrated in these regions, which cover roughly $22 \%$ of the surface area of the country. This uneven spatial distribution of economic activity is quite characteristic of a developing economy (Scott and Storper, 2007).

\footnotetext{
7 This classification is based on the resource used most intensively in the production of goods: natural resources, labour or engineering. It has been adopted by ECLAC and is largely used in Latin American studies (ECLAC, 2007). It differs slightly from the one defined by OECD.
} 
Table 2

Argentina: incumbent firms, entries and exits by group of manufacturing industries in central and peripheral regions, 2003-2008

(Number of firms and percentages)

\begin{tabular}{|c|c|c|c|c|}
\hline \multicolumn{5}{|c|}{ A. Incumbents by group of industries in central and peripheral regions, average } \\
\hline & \multicolumn{2}{|c|}{ Number of firms } & \multicolumn{2}{|c|}{ Percentage } \\
\hline & Periphery & Centre & Periphery & Centre \\
\hline Low-tech & 6534 & 22102 & 74.8 & 56.0 \\
\hline Medium-tech & 1420 & 9849 & 16.3 & 24.9 \\
\hline High-tech & 776 & 7548 & 8.9 & 19.1 \\
\hline Total & 8730 & 39500 & 100.0 & 100.0 \\
\hline \multicolumn{5}{|c|}{ B. Firm entry by group of industries in central and peripheral regions. } \\
\hline & \multicolumn{2}{|c|}{ Number of firms } & \multicolumn{2}{|c|}{ Percentage } \\
\hline & Periphery & Centre & Periphery & Centre \\
\hline Low-tech & 5071 & 16805 & 76.4 & 62.2 \\
\hline Medium-tech & 1113 & 6107 & 16.8 & 22.6 \\
\hline High-tech & 454 & 4098 & 6.8 & 15.2 \\
\hline Total & 6638 & 27010 & 100.0 & 100.0 \\
\hline \multicolumn{5}{|c|}{ C. Firm exit by group of industries in central and peripheral regions. } \\
\hline & \multicolumn{2}{|c|}{ Number of firms } & \multicolumn{2}{|c|}{ Percentage } \\
\hline & Periphery & Centre & Periphery & Centre \\
\hline Low-tech & 3088 & 10754 & 78.3 & 65.1 \\
\hline Medium-tech & 576 & 3421 & 14.6 & 20.7 \\
\hline High-tech & 279 & 2336 & 7.1 & 14.1 \\
\hline Total & 3943 & 16511 & 100.0 & 100.0 \\
\hline
\end{tabular}

Source: Prepared by the author, on the basis of data from the Employment and Business Dynamics Observatory. Note: The figures refer to population data.

In addition, the composition of incumbents, entries and exits also differs. In central provinces, the relative importance of medium- and high-tech industries is higher than in peripheral regions (see table 2). This is related to the advantages that central provinces offer to these types of activities: between them, these five regions account for $75 \%$ of expenditure in science and technology, $77 \%$ of university degrees, $62 \%$ of universities and $85 \%$ of exports of manufactured products in 2003 (INDEC, 2005). According to Feldman (1994), the geographic concentration of knowledge inputs forms a technological infrastructure that lowers the risks and costs of engaging in activities with higher levels of technological intensity.

\section{Explanatory variables}

Data from the Employment and Business Dynamics Observatory and the National Household Survey $(\mathrm{NHS})$ are used to construct the vector of explanatory variables. The distinction is important because the information contained in the EBDO database refers to the whole province, while the survey is conducted on samples of families in 31 urban areas. Nevertheless, the NHS data had to be included given the absence of a source of yearly statistical information on the demographic and/or socioeconomic characteristics of the Argentine provinces (population censuses, for example, are performed every 10 years). 
It was therefore possible to construct two types of variables: (i) region-specific variables related to the evolution of economic activity, the labour market, the level of education, the industrial structure and the existence of agglomeration economies; and (ii) sector-specific variables that account for the economic conditions faced by the three groups of industries in the different regions, such as market growth, barriers to entry and exit, industrial tradition, agglomeration effects and input prices. As discussed in section II, these factors are widely used in studies on developed countries. Moreover, year dummy variables were included to control for macroeconomic factors. ${ }^{8}$

The next step was to add variables related to poverty level, the informal economy and idle capacity in an attempt to capture the economic and structural singularities of a developing country. The square of the level of poverty and informality was also included to account for possible non-linear effects. The final step was to explore the existence of core-periphery differences by including the products of a dummy identifying the richest provinces with the variables that account for agglomeration effects and the relationship between entries and exits.

Tables 3 and 4 illustrate the definition, statistical sources and descriptive statistics of the explanatory variables. They also contain columns with the expected sign of the associated coefficient for both entry and exit. The methodologies for constructing these variables and determining the expected sign are explained briefly below.

8 These were preferred to macroeconomic variables such as GDP growth because of the measurement problems involved. The accuracy of GDP growth in local currency cannot be certified because official inflation figures have not been reliable since 2007. Similarly, GDP growth in US dollars would be misleading because of the severe devaluation of the Argentinean peso in 2002 (by more than 200\%) and the consequent gradual appreciation. 


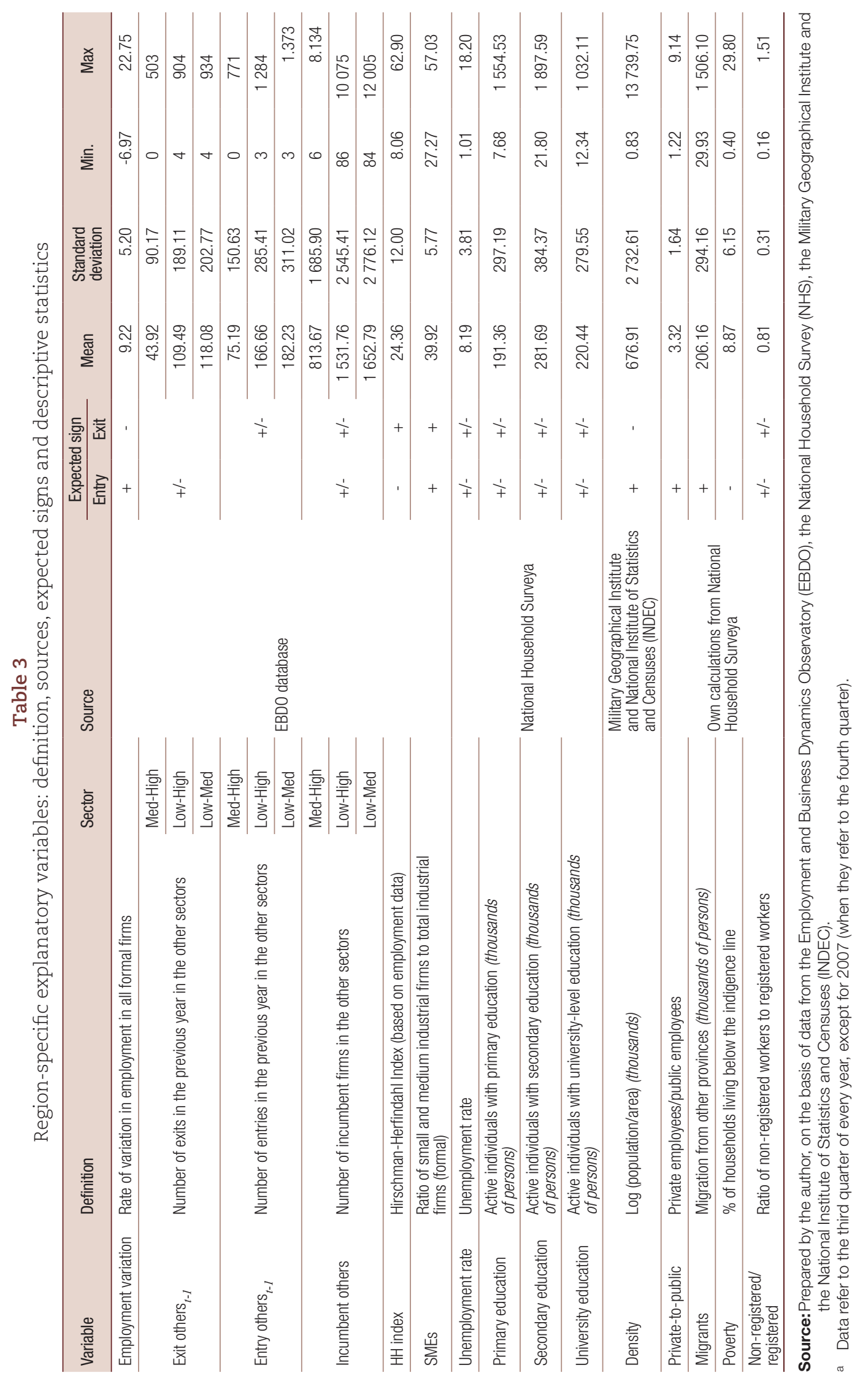




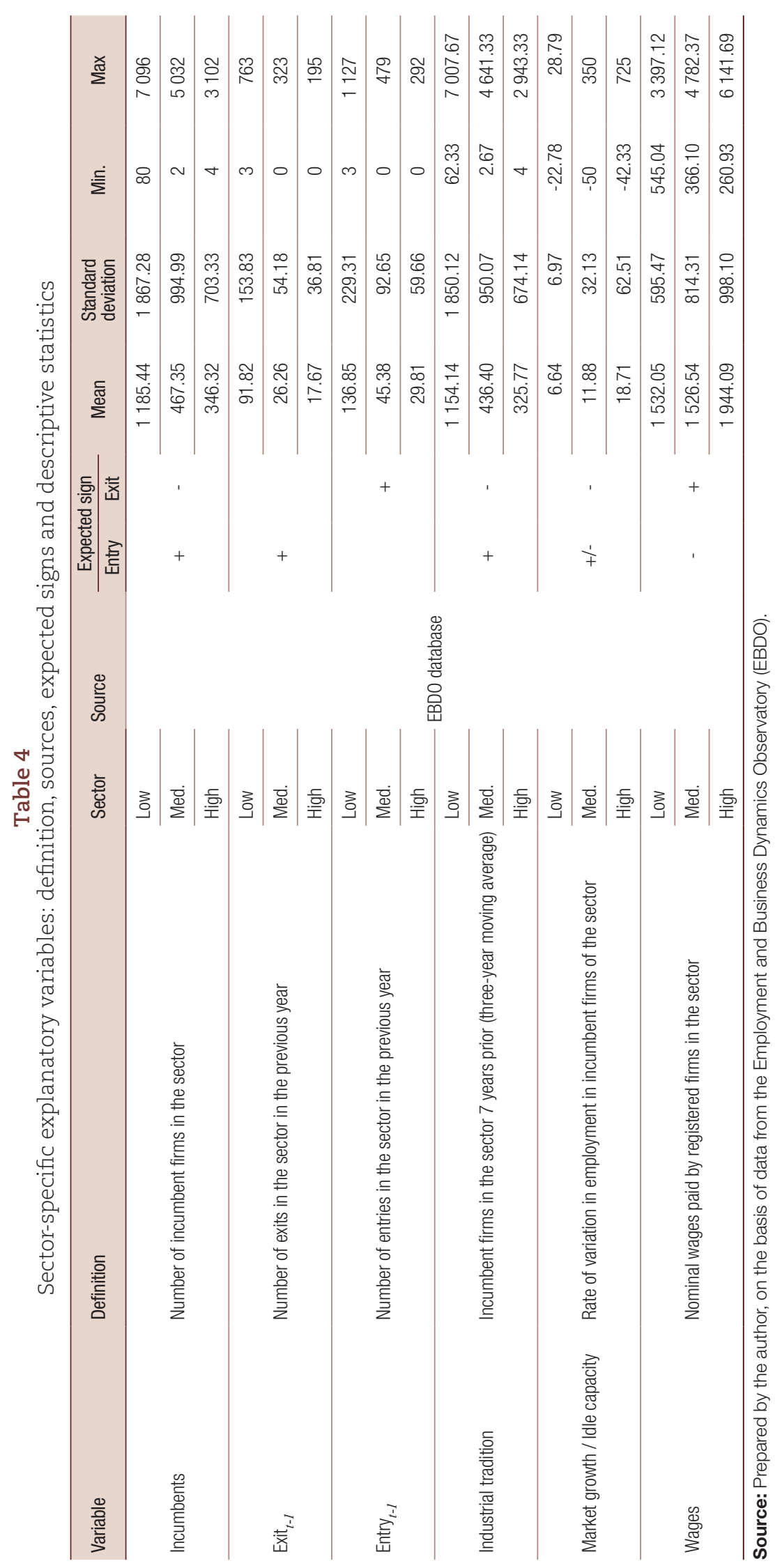




\section{(a) Region-specific variables}

Business cycle. The rate of variation of the employment in all formal firms is used as a proxy for the evolution of economic activity. The coefficient of this variable is expected to be positive for entries and negative for exits, thus reflecting the procyclicality of both processes. In addition, the (lagged) number of exits and entries are included as another proxy of regional dynamism. ${ }^{9}$

Labour. The regional unemployment rate is used to assess the labour market impact on firm dynamics. As mentioned previously, it is impossible to say a priori what that impact will be.

Education. The number of persons in the active population with primary, secondary and university-level education is used. It is expected that higher educational levels have more of an impact on high- or medium-tech activities.

Spatial concentration. Population density and its square are used as proxies for agglomeration and disagglomeration economies, respectively. It is expected that the density coefficient will be positive for entries, while both positive and negative signs are possible for exits. For the density squared coefficient, a negative sign is expected for entries and a positive for exits squared. The number of incumbent firms has also been included as an additional measure of the agglomeration of economic activity.

Industrial structure. The Hirschman-Herfindahl $(\mathrm{HH})$ index, which measures lack of diversity, is a proxy for the industrial structure of the province and the share of SMEs. It is expected that the HH index will have a negative impact on entry and a positive one on exit. The proportion of SMEs is expected to have a positive impact on both entry and exit.

Cultural attitudes. The study accounts for the regional cultural differences that may enhance start-ups by including the ratio of private-to-public employees and the number of individuals coming from other provinces. Both variables are expected to have a positive impact on entry.

Poverty. The percentage of households living below the indigence line -the threshold below which income is insufficient to afford a basic food basket, estimated at about US\$ 38 per adult in 2003- is used as a proxy for the extent of poverty. Lower entry is expected in poorer regions because the share of entrepreneurs with access to resources is smaller and the demand is lower and less diverse.

Informal economy. The ratio of non-registered workers to registered workers is used as a proxy for the regional production structure (for example, the seasonality and/or low productivity of certain activities may facilitate the growth of the informal sector) and/or the lack of government controls over informal economy. Both positive and negative signs are possible for this variable.

\section{(b) Sector-specific variables}

Previous entry/exit. The lagged number of entries (and exits) in the same group of industries are used to account for the interdependence between both processes in the exit (entry) equation. It is expected that past exit (entry) will have a positive impact on current entries (exits) because of the replacement (displacement) effect. However, this impact may be hampered if regional markets are not saturated and, consequently, competition among firms is scarce.

Spatial concentration. The number of incumbents in each group of industries is included as a proxy for the effects of localization economies and/or the level of competition among firms.

\footnotetext{
9 Note that the replacement/displacement effects are accounted for entries and exits in the same group of industries.
} 
Industrial tradition. To control for the previous industrial activities carried out in a province, the average number of incumbents in the same sector 7,6 and 5 years prior is used. Although it is expected that past incumbents encourage entry and discourage exit, high macroeconomic volatility may mitigate this effect.

Wages. The wages in each group of industries are used to assess the impact of labour cost on firm dynamics. They correspond to the average monthly wage of registered workers in the private sector, in nominal terms, given the unreliability of official inflation rates in Argentina since $2007 .{ }^{10}$ This variable is expected to have a negative impact on entries and a positive one on exits. However, its significance may be weak in developing countries, where the limitations of the financial system lead many entrepreneurs to use their savings for the initial capital required (Wang, 2006).

Market growth/idle capacity. The study uses the rate of growth of the employees in each group of industries to account for the evolution of sectoral demand. The coefficient of this variable is expected to be positive for entries and negative for exits. However, the use of idle capacity by incumbent firms may mitigate this effect in the case of entries.

\section{Econometric modelling}

The study uses panel count data models to estimate equations (1) and (2) in section III.1. ${ }^{11}$ Panel data make it possible to control for some characteristics of the provinces (observable or not) that do not change much over time, such as endowment in natural resources, institutional setting and entrepreneurial culture. Panel data also give more variability, less collinearity among the variables, more degrees of freedom and more efficiency (Baltagi, 2005).

Panel data models were preferred to cross-section estimates on the grounds of two empirical tests. First, likelihood ratio tests on the variance of the individual effects always yield statistically significant results and thus reject the validity of pooled estimates (Cameron and Trivedi, 2009). Second, the assumption that observations are indeed independent across the considered years was tested by computing the covariance matrix for the year vector of Pearson residuals from the pooled Poisson regression model (see Hausman, Hall and Griliches, 1984 for details). The findings of large values in the off-diagonal elements of the matrix in all the specifications support the independence assumption that sustains panel data models.

To choose between Poisson and negative binomial models, the ratio of the Pearson goodnessof-fit statistic to the degrees of freedom of a Poisson model was computed with province dummy variables. As Allison and Waterman (2002) argue, if this ratio is close to one, there is no evidence of overdispersion in the data and Poisson estimates are efficient. Unfortunately, negative binomial models did not achieve convergence in the low-tech entry model. The study therefore presents the results from the Poisson model -even though the ratio, at 1.42, is slightly above the value proposed by Allison and Waterman (2002). Second, the choice between fixed effects and random effects is based on the Durbin-Hu-Hausman test. For most models, it is not possible to reject the null hypothesis of no correlation between the covariates and the individual effect, which means that the random effects model yields consistent estimates. However, when that hypothesis is rejected, fixed effects models are used since they always provide consistent estimates.

\footnotetext{
10 Wages in each group of industries were constructed as a weighted average of the nominal wages in each 2-digit industry, using as weights the share of each 2-digit industry in the total number of incumbents in the group.

11 See for example, Chappell, Kimenyi and Mayer (1990); Ilmakunnas and Topi (1999); Barbosa, Guimarães and Woodward (2004); Barbosa (2007); and Fritsch and Falck (2007) for applications that use count data models to explain firm dynamics in developed countries.
} 


\section{Empirical results}

The estimates from the count models are shown in tables 5 (entry) and 6 (exit). Columns [1] present results from the specification that contains variables which are widely used in studies on developed countries, while columns [2] include variables that capture the specificities of developing countries (poverty, the size of the informal sector and idle capacity), as well as the core-periphery pattern found in Argentina (Calá, Arauzo-Carod and Manjón-Antolín, 2015 and Calá, Manjón-Antolín and Arauzo-Carod, 2016).

Table 5

Argentina: determinants of firm entry by group of industries

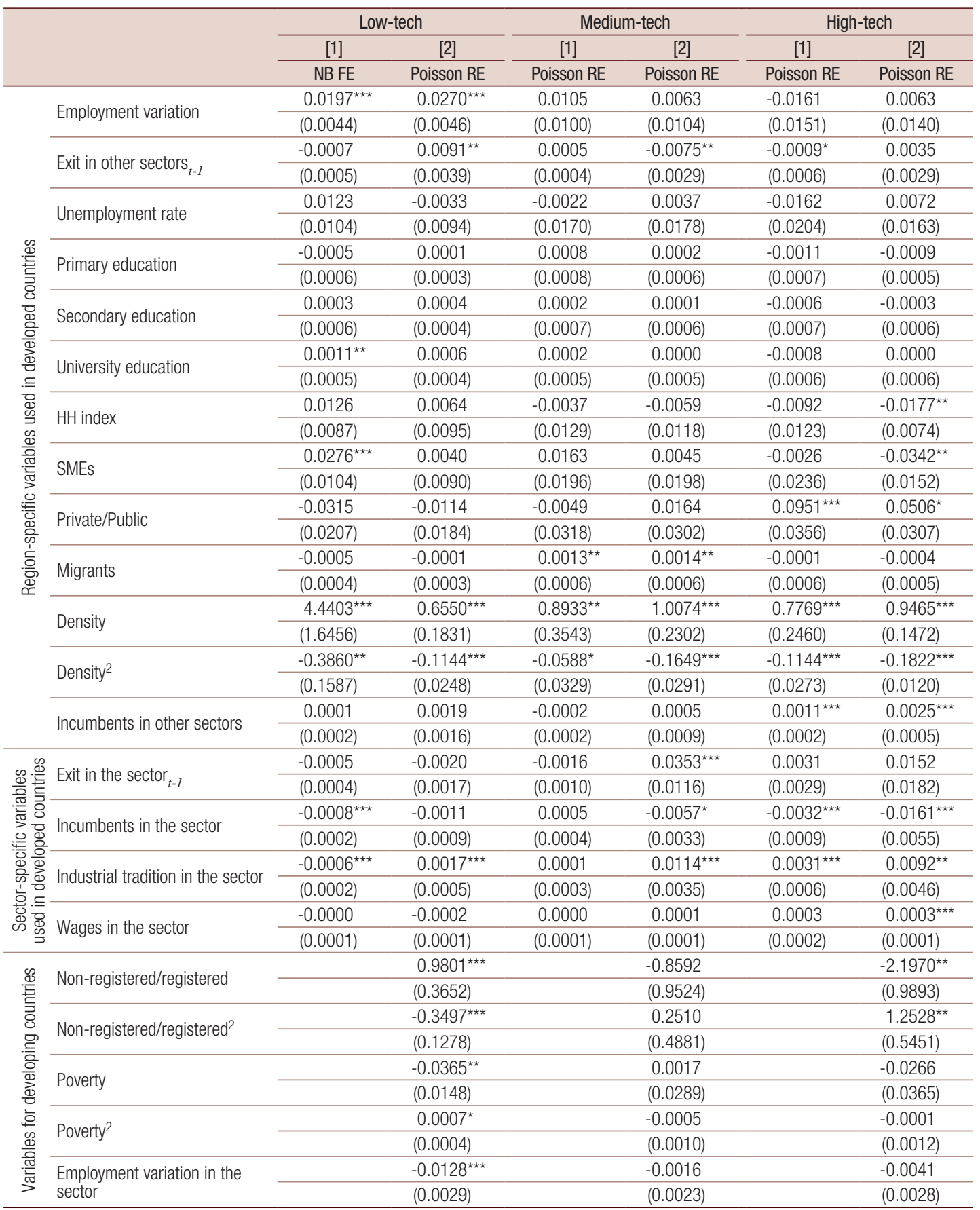


Table 5 (concluded)

\begin{tabular}{|c|c|c|c|c|c|c|c|}
\hline & \multicolumn{2}{|c|}{ Low-tech } & \multicolumn{2}{|c|}{ Medium-tech } & \multicolumn{2}{|c|}{ High-tech } \\
\hline & & [1] & [2] & {$[1]$} & [2] & [1] & [2] \\
\hline & & NB FE & Poisson RE & Poisson RE & Poisson RE & Poisson RE & Poisson RE \\
\hline \multirow{12}{*}{ 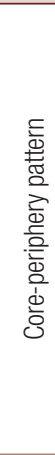 } & \multirow{2}{*}{ Density $\mathrm{x}$ rich dummy } & & $1.2746^{\star \star \star}$ & & $1.4873^{\star * \star}$ & & $1.1186^{\star \star \star}$ \\
\hline & & & $(0.3090)$ & & $(0.3274)$ & & $(0.1660)$ \\
\hline & \multirow{2}{*}{$\begin{array}{l}\text { Incumbents in other sectors } \\
x \text { rich dummy }\end{array}$} & & -0.0021 & & -0.0010 & & $-0.0022^{\star \star \star}$ \\
\hline & & & $(0.0016)$ & & $(0.0009)$ & & $(0.0006)$ \\
\hline & \multirow{2}{*}{$\begin{array}{l}\text { Incumbents in the sector } \\
\mathrm{x} \text { rich dummy }\end{array}$} & & 0.0009 & & $0.0062^{*}$ & & $0.0153^{\star \star \star}$ \\
\hline & & & $(0.0009)$ & & $(0.0033)$ & & $(0.0056)$ \\
\hline & \multirow{2}{*}{$\begin{array}{l}\text { Industrial tradition in the sector } \\
\mathrm{x} \text { rich dummy }\end{array}$} & & $-0.0019^{\star \star \star}$ & & $-0.0120^{\star \star \star}$ & & $-0.0082^{\star}$ \\
\hline & & & $(0.0006)$ & & $(0.0036)$ & & $(0.0046)$ \\
\hline & \multirow{2}{*}{$\begin{array}{l}\text { Exit in other sectors } \\
\text { dummy }\end{array}$} & & $-0.0100^{\star \star}$ & & $0.0077^{\star \star \star}$ & & -0.0036 \\
\hline & & & $(0.0039)$ & & $(0.0030)$ & & $(0.0029)$ \\
\hline & \multirow{2}{*}{$\begin{array}{l}\text { Exit in the sector }{ }_{t-1} \times \text { rich } \\
\text { dummy }\end{array}$} & & 0.0019 & & $-0.0377^{\star \star \star}$ & & -0.0147 \\
\hline & & & $(0.0017)$ & & $(0.0117)$ & & $(0.0185)$ \\
\hline \multicolumn{2}{|c|}{ AlC } & 884.57 & 1207.37 & 913.67 & 880.80 & 735.47 & 682.64 \\
\hline \multicolumn{2}{|c|}{ LR Test } & $172.37^{\star \star \star}$ & $448.47^{\star \star \star}$ & $98.57^{\star \star \star}$ & $273.46^{\star \star \star}$ & $205.53^{\star \star \star}$ & $5107.27^{\star \star \star}$ \\
\hline \multicolumn{2}{|c|}{ Hausman } & $142.67^{\star \star \star}$ & 10.82 & (a) & 0.93 & 8.80 & $27.74^{\star}$ \\
\hline \multicolumn{2}{|c|}{ Pearson ratio } & 1.85 & 1.42 & 1.12 & 0.95 & 0.98 & 0.92 \\
\hline
\end{tabular}

Source: Prepared by the author.

Note: Observations: 144. In high-tech industry the number of observations is 138 in FE models. Standard errors in brackets. Asterisks indicate the statistical significance of the coefficient: ${ }^{\star \star \star} p$-value $<0.01,{ }^{\star *} p$-value $<0.05,{ }^{*} p$-value $<0.1$. Year dummy variables are included in all the specifications.

a Negative unreported statistic found.

Table 6

Argentina: determinants of firm exit by group of industries

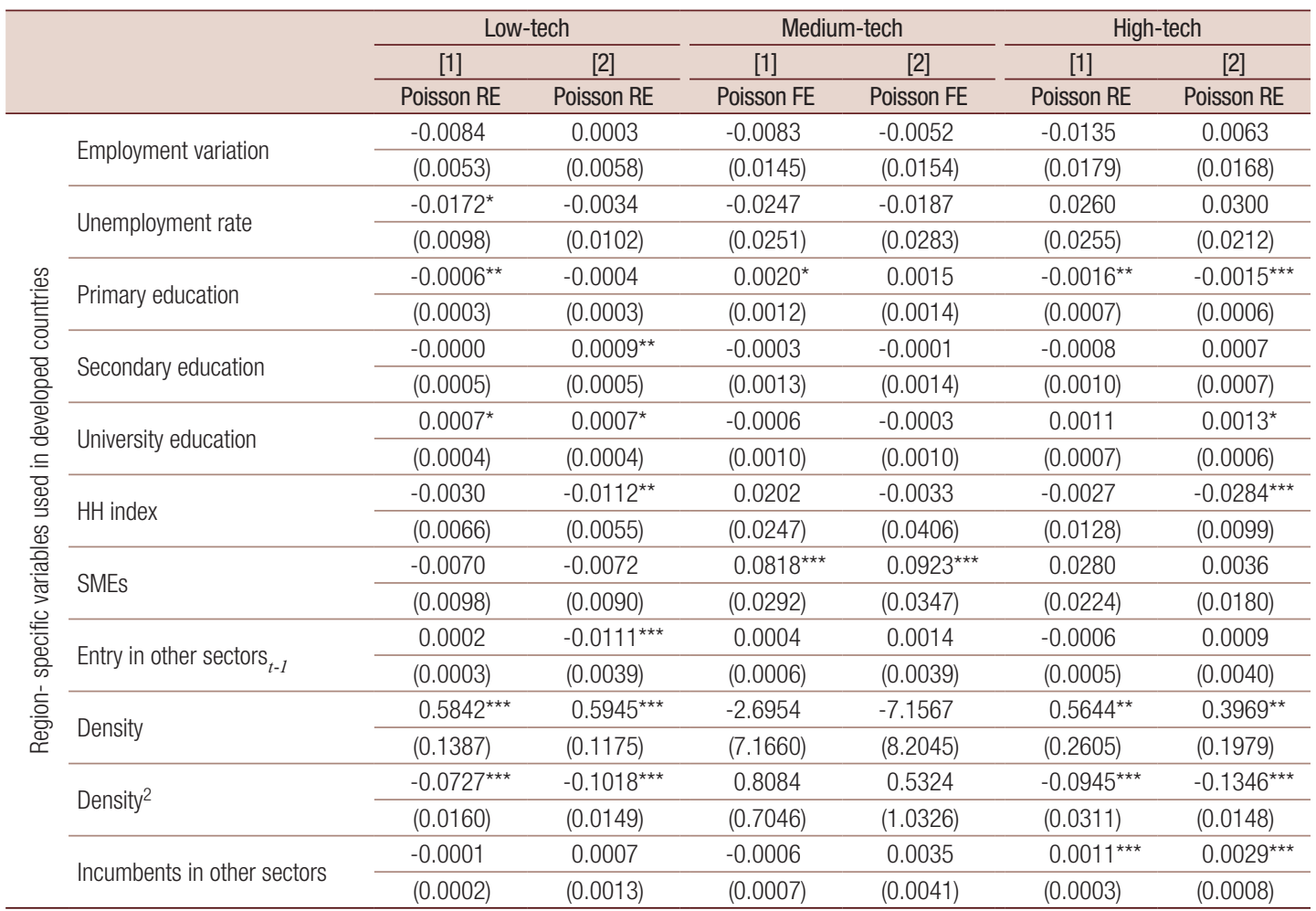


Table 6 (concluded)

\begin{tabular}{|c|c|c|c|c|c|c|c|}
\hline & \multicolumn{2}{|c|}{ Low-tech } & \multicolumn{2}{|c|}{ Medium-tech } & \multicolumn{2}{|c|}{ High-tech } \\
\hline & & [1] & [2] & [1] & [2] & [1] & [2] \\
\hline & & Poisson RE & Poisson RE & Poisson FE & Poisson FE & Poisson RE & Poisson RE \\
\hline \multirow{8}{*}{ 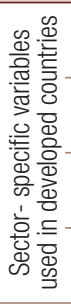 } & \multirow{2}{*}{ Entry in the sector ${ }_{t-1}$} & $-0.0004^{* *}$ & $0.0057^{\star \star *}$ & -0.0014 & 0.0215 & 0.0017 & 0.0164 \\
\hline & & $(0.0002)$ & $(0.0019)$ & $(0.0016)$ & $(0.0137)$ & $(0.0021)$ & $(0.0213)$ \\
\hline & \multirow{2}{*}{ Incumbents in the sector } & $0.0006^{\star \star \star}$ & -0.0001 & 0.0009 & $-0.0259^{* *}$ & $-0.0030^{* * *}$ & $-0.0317^{\text {***}}$ \\
\hline & & $(0.0001)$ & $(0.0008)$ & $(0.0013)$ & $(0.0111)$ & $(0.0010)$ & $(0.0072)$ \\
\hline & \multirow{2}{*}{ Industrial tradition in the sector } & $0.0003^{* * *}$ & $0.0012^{\star \star}$ & 0.0000 & -0.0145 & $0.0025^{\star \star \star}$ & $0.0237^{* \star *}$ \\
\hline & & $(0.0001)$ & $(0.0005)$ & $(0.0005)$ & $(0.0118)$ & $(0.0006)$ & $(0.0063)$ \\
\hline & \multirow{2}{*}{ Wages in the sector } & -0.0000 & 0.0000 & $0.0004^{* \star}$ & 0.0002 & 0.0000 & 0.0001 \\
\hline & & $(0.0001)$ & $(0.0002)$ & $(0.0002)$ & $(0.0002)$ & $(0.0002)$ & $(0.0001)$ \\
\hline \multirow{6}{*}{ 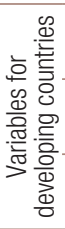 } & \multirow{2}{*}{ Non-registered/registered } & & $-0.7609^{\star *}$ & & 0.0321 & & -0.6109 \\
\hline & & & $(0.3716)$ & & (1.3403) & & $(1.0707)$ \\
\hline & \multirow{2}{*}{ Non-registered/registered² } & & $0.2633^{\star *}$ & & 0.3837 & & 0.5845 \\
\hline & & & $(0.1307)$ & & $(0.6865)$ & & $(0.5986)$ \\
\hline & \multirow{2}{*}{$\begin{array}{l}\text { Employment variation } \\
\text { in the sector }\end{array}$} & & $-0.0076^{\star \star}$ & & -0.0054 & & -0.0017 \\
\hline & & & $(0.0038)$ & & $(0.0041)$ & & $(0.0027)$ \\
\hline \multirow{12}{*}{ 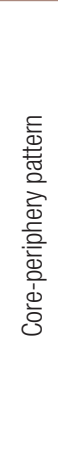 } & \multirow{2}{*}{ Density x rich dummy } & & $0.9750^{\star \star \star}$ & & 8.4807 & & $1.3593^{\star \star \star}$ \\
\hline & & & $(0.2539)$ & & (9.0378) & & $(0.1866)$ \\
\hline & \multirow{2}{*}{$\begin{array}{l}\text { Incumbents in other sectors } \\
\text { x rich dummy }\end{array}$} & & -0.0010 & & -0.0054 & & $-0.0032^{\star * *}$ \\
\hline & & & $(0.0013)$ & & $(0.0042)$ & & $(0.0008)$ \\
\hline & \multirow{2}{*}{$\begin{array}{l}\text { Incumbents in the sector } \\
\mathrm{x} \text { rich dummy }\end{array}$} & & 0.0001 & & $0.0268^{\star *}$ & & $0.0319^{\star \star \star}$ \\
\hline & & & (0.0008) & & $(0.0113)$ & & $(0.0073)$ \\
\hline & \multirow{2}{*}{$\begin{array}{l}\text { Industrial tradition in the sector } \\
\text { x rich dummy }\end{array}$} & & $-0.0014^{\star \star *}$ & & 0.0130 & & $-0.0232^{\star \star *}$ \\
\hline & & & $(0.0005)$ & & (0.0118) & & $(0.0062)$ \\
\hline & \multirow{2}{*}{$\begin{array}{l}\text { Entry in other sectors } \\
\mathrm{x} \text { rich dummy }\end{array}$} & & $0.0116^{\star \star *}$ & & -0.0001 & & -0.0006 \\
\hline & & & $(0.0039)$ & & $(0.0038)$ & & $(0.0040)$ \\
\hline & \multirow{2}{*}{$\begin{array}{l}\text { Entry in the sector } \\
x \text { rich dummy }\end{array}$} & & $-0.0057^{\star \star \star *}$ & & -0.0217 & & -0.0160 \\
\hline & & & $(0.0019)$ & & $(0.0138)$ & & $(0.0213)$ \\
\hline \multicolumn{2}{|c|}{ AIC } & 1063.37 & 1041.07 & 511.04 & 515.48 & 641.38 & 608.10 \\
\hline \multicolumn{2}{|c|}{ LR Test LR Test } & $1350.86^{\star \star \star}$ & $1794.58^{\star \star \star}$ & $511.45^{\star \star \star}$ & $522.85^{\star \star \star}$ & $375.29^{\star \star \star}$ & $3421.43^{\star \star \star}$ \\
\hline \multicolumn{2}{|c|}{ Hausman } & $19.25^{\star}$ & 20.51 & $35.22^{\star \star \star}$ & $110.87^{\star \star \star}$ & 14.70 & 19.30 \\
\hline \multicolumn{2}{|c|}{ Pearson ratio } & 1.25 & 1.07 & 0.86 & 0.83 & 0.88 & 0.86 \\
\hline
\end{tabular}

Source: Prepared by the author.

Note: Observations: 144. Standard errors in brackets. Asterisks indicate the statistical significance of the coefficient: ${ }^{* * *} \mathrm{p}$-value $<0.01,{ }^{* *} \mathrm{p}$-value $<0.05,{ }^{*} \mathrm{p}$-value $<0.1$. Year dummy variables are included in all the specifications.

Upon analysis of the findings for firm entry (table 5, columns [2]), it becomes apparent that results for low-tech activities, which account for approximately $65 \%$ of total entries over the period under consideration, are largely consistent with those found in previous studies on the manufacturing sector as a whole (Calá, Manjón-Antolín and Arauzo-Carod, 2016). However, the impact of the covariates is not homogeneous across sectors. For example, the evolution of regional demand is relevant only to low-tech activities, while structural variables (such as the share of SMEs or industrial diversification), cultural factors (such as the private/public ratio or the share of migrants), or the level of wages are relevant only to medium- and high-tech industries. This implies that a favourable economic environment enhances firm creation only in traditional sectors, but it is not enough to promote regional structural changes driven by firm entries in medium- and high-tech industries.

There are also significant agglomeration and dispersal effects driven by population density. The former are particularly strong in central regions, where a higher population density encourages entry even more than in the periphery. In central provinces, agglomeration economies in medium- and high-tech industries are also driven by the number of incumbents in the same sector (localization economies). Interestingly, agglomeration effects for high-tech activities also emerge from the concentration of firms in other sectors, consistent with the idea of urbanization economies, as in developed countries (Henderson, 
Kuncoro and Turner, 1995). This finding suggests the relevance of regional diversification to promoting new high-tech ventures, and it is consistent with the negative impact of industrial concentration on high-tech entries.

Variables that are a proxy for the singularities of Argentina as a developing country are highly significant, particularly in low-tech industries. For example, the negative sign of the poverty variable is consistent with lower purchasing power and fewer financial, human and social capital resources available for entrepreneurs in poor areas. Furthermore, the positive effect of the squared term suggests that high levels of poverty spur the creation of (possibly small) firms with low entry barriers. The impact of the informal economy is also non-linear. A small informal economy encourages entry by either pushing people towards entrepreneurship or providing the opportunity of sub-contracting activities. However, when there is excessive growth of the informal sector, competition with informal firms may impede the entry of formal ventures. ${ }^{12}$ Notably, this variable has contrasting impacts on high-tech entries and on low-tech activities. In addition, as employment in the sector increases, fewer low-tech entries are expected, which suggests that the higher sectoral demand is satisfied through the use of idle capacity rather than through new firm formation.

Finally, many variables including replacement effects and past and current agglomeration economies show opposite effects in the core and the periphery, a detail that is overlooked in specifications that do not distinguish between both groups of provinces and thus overlap the positive/negative effects. The findings show that it may be particularly difficult to promote high-tech entry in lagged regions because there are usually not enough related firms to create the necessary conditions for external economies of scale.

Table 6 shows analogous results for firm exit. Once again, results for firm exit in low-tech activities (which account for $68 \%$ of total exits) are consistent with those found in previous studies focusing on aggregated exit (Calá, Arauzo-Carod and Manjón-Antolín, 2015). In particular, previous entrants in the sector generate a replacement effect in peripheral regions but prevent exit in the core. This suggests that the revolving door is more intense in poorer regions and the (presumably) shorter survival is possibly related to the small market size in these lagged regions. The above casts doubts on the usefulness in these regions of entry-promoting policies that, ultimately, may only cause more exits. The industrial tradition and entries in other sectors also have opposite effects on both core and peripheral provinces. In particular, the negative impact of previous entry observed in the periphery may be a proxy for the outlook for regional manufacturing activity. In addition, the findings point to a negative effect of the degree of industrial concentration and market growth on exit, while the educational level of the workforce has a positive impact. This may be related to tougher competition in areas with higher levels of human capital.

Dense areas force firms out of the market, although this effect is reversed in areas of very high density. This outcome may be attributed to competition effects and to differences within a given province, for example between dense areas specialized in services (especially public services) and less populated industrial regions, where manufacturing activity is more easily retained. At any rate, this is a topic worthy of future research. The dispersal effect, in particular, is more pronounced in core regions, where population density fosters exit even more than in the rest of the country.

Lastly, the informal economy has much the same impact on low-tech exit as it does on the whole manufacturing as a whole (Calá, Arauzo-Carod and Manjón-Antolín, 2015). Although a small informal economy prevents exit, its effect is the opposite when it grows beyond a certain level. The initial negative effect on exit may be related to the inherently lower costs and/or the greater flexibility of hiring in the informal sector, while a positive impact is expected when formal firms have to compete for resources or market access with informal firms. Remarkably, the links between the formal and the informal sector seem to be relevant only in low-tech industries.

\footnotetext{
${ }^{12}$ A larger informal sector may also reflect the lack of government controls in certain provinces, which may discourage entrepreneurs from establishing formal firms.
} 
As in the entry process, exits in medium-tech sectors are far less systematic than in the other sectors. ${ }^{13}$ There is a positive effect of the share of SMEs, which reflects the "liability of smallness" (Strotmann, 2007). There is also a competition effect driven by incumbents in core areas, while the opposite effect is found in the periphery, where localization economies seem to be more important.

Exits in high-tech industries are largely driven by agglomeration diseconomies arising from population density and the number of incumbent firms in other sectors. However, there are marked differences between the core and the periphery. In the central areas, incumbents in the same sector push firms out of the market (competition effect), whereas in peripheral provinces those incumbents induce localization economies that prevent exit. At the same time, incumbents in other sectors retain firms in core provinces (which is the expected outcome of a dense industrial structure or the existence of urbanization economies), but they foster exit in non-central regions. Industrial tradition in the sector is also relevant and it has the opposite impact in central area (negative) and the periphery (positive). These results suggest that some case studies on high-tech ventures both in core and peripheral regions may shed light on the shortcomings that these firms face in both groups of provinces.

\section{Conclusion}

This paper analyses the determinants of entry and exit in developing countries, using Argentina as an illustrative case. This is, to our knowledge, the first attempt to explain regional firm dynamics in a developing economy using both regional and sectoral variables.

The results suggest that several specificities of developing economies should be taken into account in order to explain firm dynamics in these countries. In Argentina, for example, the findings reveal a substitution effect between the use of idle capacity and new firm formation, as well as a non-linear impact of the poverty level on entries. The latter means that policies aimed simply at promoting new business creation may have limited bearing, since reducing poverty rates probably requires long-term measures. Moreover, the results indicate that the size of the informal sector has a non-linear effect on both entry and exit with differences for low- and high-tech sectors. This suggests that the links between the formal and the informal sectors may be extremely complex and that more research is needed to understand this strong relationship.

The study also shows that different factors explain firm entry and exit in low- and high-tech industries. In particular, variables specific to developing countries have an impact mostly on low-tech entries and exits. This suggests that policy measures aimed at fostering start-ups and preventing firm exit may succeed only if they take into account the industrial mix of each geographical area.

Lastly, there is evidence of a core-periphery pattern in which many variables have opposite effects in central and lagged provinces. This means that the geographical effects on firm dynamics cannot be adequately assessed if there is no distinction between central and peripheral regions. Consequently, entrepreneurship policies for the whole country should not be based on results and experiences taken only from central regions.

Future extensions of this study should test for the equality of the effects of the explanatory variables on non-local manufacturing firms and on the service sector. Further research should also analyse the impact of regional firm dynamics on some measures of economic performance, such as employment creation or regional innovation.

\footnotetext{
${ }^{13}$ The fact that medium-tech activities probably share certain characteristics with both low- and high-tech industries makes it more difficult to identify firm dynamics determinants in this group of industries.
} 


\section{Bibliography}

Agarwal, R. and M. Gort (1996), "The evolution of markets and entry, exit and survival of firms", The Review of Economics and Statistics, vol. 78, No. 3, Cambridge, Massachusetts, The MIT Press.

Allison, P. D. and R. P. Waterman (2002), "Fixed-effects negative binomial regression models", Sociological Methodology, vol. 32, No. 1, Wiley.

Álvarez, R. and S. Vergara (2013), "Trade exposure, survival and growth of small and medium-size firms", International Review of Economics \& Finance, vol. 25, Amsterdam, Elsevier.

(2010), "Exit in developing countries: economic reforms and plant heterogeneity", Economic Development and Cultural Change, vol. 58, No. 3, Chicago, The University of Chicago Press.

Arauzo-Carod, J. M. and others (2007), "Regional and sector-specific determinants of industry dynamics and the displacement-replacement effects", Empirica, vol. 34, No. 2, Springer.

Armington, C. and Z. J. Acs (2002), "The determinants of regional variation in new firm formation", Regional Studies, vol. 36, No. 1, Taylor \& Francis.

Audretsch, D. B. (1995a), "Innovation, growth and survival", International Journal of Industrial Organization, vol. 13, No. 4, Amsterdam, Elsevier. (1995b), Innovation and Industry Evolution, Cambridge, Massachusetts, The MIT Press.

Audretsch, D. B. and M. Fritsch (1999), "The industry component of regional new firm formation processes", Review of Industrial Organization, vol. 15, No. 3, Springer.

Audretsch, D. B. and M. Keilbach (2005), "Entrepreneurship capital and regional growth", The Annals of Regional Science, vol. 39, No. 3, Springer.

Baltagi, B. H. (2005), Econometric Analysis of Panel Data, Chichester, Wiley.

Barbosa, N. (2007), "An integrative model of firms' entry decisions", Applied Economics Quarterly, vol. 53, No. 1, Berlin, Duncker \& Humblot.

Barbosa, N., P. Guimarães and D. Woodward (2004), "Foreign firm entry in an open economy: the case of Portugal", Applied Economics, vol. 36, No. 5, Taylor \& Francis.

Bennett, J. (2010), "Informal firms in developing countries: entrepreneurial stepping stone or consolation prize?", Small Business Economics, vol. 34, No. 1, Springer.

Bresnahan, T. F. and P. C. Reiss (1991), "Entry and competition in concentrated markets", Journal of Political Economy, vol. 99, No. 5, Chicago, The University of Chicago Press.

Brixy, U. and R. Grotz (2007), "Regional patterns and determinants of birth and survival of new firms in Western Germany", Entrepreneurship \& Regional Development, vol. 19, No. 4, Taylor \& Francis.

Bruton, G. D., D. Ahlstrom and K. Obloj (2008), "Entrepreneurship in emerging economies: where are we today and where should the research go in the future", Entrepreneurship Theory and Practice, vol. 32, No. 1, Wiley.

Buss, T. F. and X. Lin (1990), "Business survival in rural America: a three-state study", Growth and Change, vol. 21, No. 3, Wiley.

Calá, C. D., J. M. Arauzo-Carod and M. Manjón-Antolín (2015), "The determinants of exit in a developing country: core and peripheral regions", The Annals of Regional Science, vol. 54, No. 3, Springer.

Calá, C. D., M. Manjón-Antolín and J. M. Arauzo-Carod (2016), "Regional determinants of firm entry in a developing country", Papers in Regional Science, vol. 95, No. 2, Wiley.

Cameron, A. C. and P. K. Trivedi (2009), Microeconometrics Using Stata, Texas, Stata Press.

Carree, M., S. Santarelli and I. Verheul (2008), "Firm entry and exit in Italian provinces and the relationship with unemployment", International Entrepreneurship Management Journal, vol. 4, No. 2, Springer.

Carree, M. and R. Thurik (1996), "Entry and exit in retailing: incentives, barriers, displacement and replacement", Review of Industrial Organization, vol. 11, No. 2, Springer.

Carree, M., I. Verheul and E. Santarelli (2011), "Sectoral patterns of firm exit in Italian provinces", Journal of Evolutionary Economics, vol. 21, No. 3, Springer.

Cassiolato, J. E., C. B. Pagola and H. M. Lastres (2009), "Technical change and structural inequalities: converging approaches to problems of underdevelopment", Techno-Economic Paradigms: Essays in Honour of Carlota Perez, W. J. Drechsler, R. Kattel and E. S. Reinert (eds.), London, Anthem Press.

Chappell, W., M. Kimenyi and W. Mayer (1990), "A poisson probability model of entry and market structure with an application to U.S. industries during 1972-77", Southern Economic Journal, vol. 56, No. 4, Chattanooga, Tennessee, Southern Economic Association. 
ECLAC (Economic Commission for Latin America and the Caribbean) (2007), "Progreso técnico y cambio estructural en América Latina y el Caribe", Project Documents (LC/W.136), Santiago.

Eslava, M. and others (2006), "Plant turnover and structural reforms in Colombia", IMF Staff Papers, No. 53, special issue, Washington, D.C., International Monetary Fund (IMF).

Feldman, M. P. (1994), The Geography of Innovation, vol. 2, Springer.

Forsyth, G. D. (2005), "A note on small business survival rates in rural areas: the case of Washington state", Growth and Change, vol. 36, No. 3, Wiley.

Fotopoulos, G. and N. Spence (1998), "Accounting for net entry into Greek manufacturing by establishments of varying size", Small Business Economics, vol. 11, No. 2, Springer.

Frazer, G. (2005), "Which firms die? A look at manufacturing firm exit in Ghana", Economic Development and Cultural Change, vol. 53, No. 3, Chicago, The University of Chicago Press.

Fritsch, M. and O. Falck (2007), "New business formation by industry over space and time: a multidimensional analysis", Regional Studies, vol. 41, No. 2, Taylor \& Francis.

Fritsch, M., U. Brixy and O. Falck (2006), "The effect of industry, region, and time on new business survival. A multi-dimensional analysis", Review of Industrial Organization, vol. 28, No. 3, Springer.

Ghani, E., W. Kerr and S. O'Connell, (2014), "Spatial determinants of entrepreneurship in India", Regional Studies, vol. 48, No. 6, Taylor \& Francis.

Günalp, B. and S. M. Cilasun (2006), "Determinants of entry in Turkish manufacturing industries", Small Business Economics, vol. 27, No. 2-3, Springer.

Hausman, J., B. H. Hall and Z. Griliches (1984), "Econometric models for count data with an application to the patents-R \& D relationship", Econometrica, vol. 52, No. 4, New York, The Econometric Society.

Henderson, V., A. Kuncoro and M. Turner (1995), "Industrial development in cities", Journal of Political Economy, vol. 103, No. 5, Chicago, The University of Chicago Press.

Huiban, J. P. (2011), "The spatial demography of new plants: urban creation and rural survival", Small Business Economics, vol. 37, No. 1, Springer.

Ilmakunnas, P. and J. Topi (1999), "Microeconomic and macroeconomic influences on entry and exit of firms", Review of Industrial Organization, vol. 15, No. 3, Springer.

INDEC (National Institute of Statistics and Censuses) (2005), Anuario Estadístico de la República Argentina, Buenos Aires.

Kantis, H., P. Angelelli and V. Moori Koening (2005), Developing Entrepreneurship: Experience in Latin America and Worldwide, Washington, D.C., Inter-American Development Bank (IDB).

Katz, J. and G. Bernat (2011), "Exit-entry, productivity growth and structural change in response to changes in macroeconomic policy: evidence from Argentina", Innovation and Development, vol. 1, No. 2, Taylor \& Francis.

Katz, J. and G. Stumpo (2001), "Sectoral regimes, productivity and international competitiveness", CEPAL Review, No. 75 (LC/G.2150-P), Santiago, Economic Commission for Latin America and the Caribbean (ECLAC).

Keeble, D. and S. Walker (1994), "New firms, small firms and dead firms: spatial patterns and determinants in the United Kingdom", Regional Studies, vol. 28, No. 4, Taylor \& Francis.

Kosacoff, B. and A. Ramos (1999), "The industrial policy debate", CEPAL Review, No. 68 (LC/G.2039-P), Santiago, Economic Commission for Latin America and the Caribbean (ECLAC).

Lay, T. J. (2003), "The determinants of and interaction between entry and exit in Taiwan's manufacturing", Small Business Economics, vol. 20, No. 4, Springer.

Littunen, H., E. Storhammar and T. Nenonen (1998), "The survival of firms over the critical first 3 years and the local environment", Entrepreneurship \& Regional Development vol. 10, No. 3, Taylor \& Francis.

López, R. A. (2006), "Imports of intermediate inputs and plant survival", Economics Letters, vol. 92, No. 1, Amsterdam, Elsevier.

MTEySS (Ministry of Labour, Employment and Social Security) (2007), "La creación de empresas durante la etapa post convertibilidad (2003-2005): impacto sobre el empleo asalariado registrado", Trabajo, ocupación y empleo. Salarios, empresas y empleo 2003-2006, Estudios series, No. 5, Buenos Aires.

Naudé, W. and others (2008), "Regional determinants of entrepreneurial start-ups in a developing country", Entrepreneurship \& Regional Development: An International Journal, vol. 20, No. 2, Taylor \& Francis.

Nurmi, S. (2006), "Sectoral differences in plant start-up size in the Finnish economy", Small Business Economics, vol. 26, No. 1, Springer.

Nyström, K. (2007), "An industry disaggregated analysis of the determinants of regional entry and exit", Annals of Regional Science, vol. 41, No. 4, Springer. 
Ocampo, J. A., C. Rada and L. Taylor (2009), Growth and Policy in Developing Countries: A Structuralist Approach, New York, Columbia, University Press.

Ozturk, S. and C. Kilic (2012), "Patterns and determinants of entry and exit in Turkish manufacturing industries", International Journal of Arts and Commerce, vol. 1, No. 5 [online] http://ijac.org.uk/images/frontlmages/ gallery/Nol._1_No._5/11.pdf.

Reynolds, P., D. J. Storey and P. Westhead (1994), "Cross-national comparisons of the variation in new firm formation rates", Regional Studies, vol. 28, No. 4, Taylor \& Francis.

Rocha, H. O. and R. Sternberg (2005), "Entrepreneurship: the role of clusters theoretical perspectives and empirical evidence from Germany", Small Business Economics, vol. 24, No. 3, Springer.

Santarelli, E., M. Carree and I. Verheul (2009), "Unemployment and firm entry and exit: an update on a controversial relationship", Regional Studies, vol. 43, No. 8, Taylor \& Francis.

Santarelli, E. and H. T. Tran (2012), "Growth of incumbent firms and entrepreneurship in Vietnam", Growth and Change, vol. 43, No. 4, Wiley.

Schneider, F. (2005), "Shadow economies around the world: what do we really know?", European Journal of Political Economy, vol. 21, No. 3, Amsterdam, Elsevier.

Scott, A. J. and M. Storper (2007), "Regions, globalization, development", Regional Studies, vol. 41(S1), Taylor \& Francis.

Shapero, A. (1983), New Business Formation, Enschede.

Spilling, O. R. (1996), "Regional variation of new firm formation: the Norwegian case", Entrepreneurship and Regional Development, vol. 8, No. 3, Taylor \& Francis.

Stiglitz, J. (1998), "Towards a new paradigm for development: strategies, policies, and processes" [online] http://citeseerx.ist.psu.edu/viewdoc/download?doi=10.1.1.199.9708\&rep=rep1\&type=pdf.

Strotmann, H. (2007), "Entrepreneurial survival", Small Business Economics, vol. 28, No. 1, Springer.

Sunkel, O. (1978), "La dependencia y la heterogeneidad estructural”, Trimestre Económico, vol. 45, No. 177(1), Mexico City, Fondo de Cultura Económica.

Vernon, R. (1966), "International investment and international trade in the product cycle", The Quarterly Journal of Economics, vol. 80, No. 2, Oxford, Oxford University Press.

Wang, S. (2006), "Determinants of new firm formation in Taiwan", Small Business Economics, vol. 27, No. 4-5, Springer.

Wilson, D. and R. Purushothaman (2006), "Dreaming with BRICs: the path to 2050", Emerging Economies and the Transformation of International Business. Brazil, Russia, India and China, S. Jain (ed.), Cheltenham, Edward Elgar Publishing Ltd. 


\section{Annex A1}

Table A1.1

Argentina: industry classification, 2008

(Percentages)

\begin{tabular}{|c|c|c|c|c|}
\hline Group & Code & Industry & Firms & Employees \\
\hline \multirow{10}{*}{ Low tech } & 15 & Manufacture of food products and beverages & 22.6 & 26.6 \\
\hline & 16 & Manufacture of tobacco products & 0.0 & 0.4 \\
\hline & 17 & Manufacture of textiles & 4.9 & 5.5 \\
\hline & 18 & Manufacture of wearing apparel; dressing and dyeing of fur & 6.8 & 4.5 \\
\hline & 19 & $\begin{array}{l}\text { Tanning and dressing of leather; manufacture of luggage, handbags, saddlery, } \\
\text { harness and footwear }\end{array}$ & 3.0 & 3.3 \\
\hline & 20 & $\begin{array}{l}\text { Manufacture of wood and of products of wood and cork, except furniture; } \\
\text { manufacture of articles of straw and plaiting materials }\end{array}$ & 5.9 & 3.2 \\
\hline & 22 & Publishing, printing and reproduction of recorded media & 6.9 & 4.8 \\
\hline & 26 & Manufacture of other non-metallic mineral products & 3.3 & 3.4 \\
\hline & 36 & Manufacture of furniture; manufacturing n.e.c. & 5.7 & 3.4 \\
\hline & 37 & Recycling & 0.3 & 0.3 \\
\hline \multicolumn{2}{|c|}{ Total Low Tech } & & 59.4 & 55.4 \\
\hline \multirow{5}{*}{ Medium tech } & 21 & Manufacture of paper and paper products & 1.5 & 2.5 \\
\hline & 23 & Manufacture of coke, refined petroleum products and nuclear fuel & 0.1 & 0.5 \\
\hline & 25 & Manufacture of rubber and plastics products & 5.3 & 5.4 \\
\hline & 27 & Manufacture of basic metals & 2.1 & 3.5 \\
\hline & 28 & Manufacture of fabricated metal products, except machinery and equipment & 14.4 & 8.7 \\
\hline \multicolumn{2}{|c|}{ Total Medium Tech } & & 23.4 & 20.6 \\
\hline \multirow{8}{*}{ High tech } & 24 & Manufacture of chemicals and chemical products & 4.1 & 7.0 \\
\hline & 29 & Manufacture of machinery and equipment n.e.c. & 5.8 & 5.9 \\
\hline & 30 & Manufacture of office, accounting and computing machinery & 0.3 & 0.3 \\
\hline & 31 & Manufacture of electrical machinery and apparatus n.e.c. & 1.9 & 1.9 \\
\hline & 32 & Manufacture of radio, television and communication equipment and apparatus & 0.2 & 0.4 \\
\hline & 33 & Manufacture of medical, precision and optical instruments, watches and clocks & 1.0 & 0.7 \\
\hline & 34 & Manufacture of motor vehicles, trailers and semi-trailers & 2.8 & 6.7 \\
\hline & 35 & Manufacture of other transport equipment & 0.8 & 1.0 \\
\hline \multicolumn{2}{|c|}{ Total High Tech } & & 16.9 & 23.9 \\
\hline
\end{tabular}

Source: Prepared by the author, on the basis of United Nations, "International Standard Industrial Classification of All Economic Activities, third revision”, Statistical Papers, Series M, No.4, Rev. 3 (ST/ESA/STAT/SER.M/4/Rev.3), New York, 1990; data from the Employment and Business Dynamics Observatory; and J. Katz and G. Bernat, "Exit-entry, productivity growth and structural change in response to changes in macroeconomic policy: evidence from Argentina", Innovation and Development, vol. 1, No. 2, Taylor \& Francis, 2011.

Note: $\quad$ Data $=$ Entry + Incumbent - Exit. 